\title{
Intelligent Analysis of Some Factors Characterizing Patients Operated For Varicose Veins at Setif University Hospital -Algeria
}

\author{
El-Hachmi Seddik $^{{ }^{*}, \text { Khenchouche Abelhalim}^{2} \text {, Bahar Abdelaziz }}{ }^{1}$ \\ ${ }^{1}$ Surgery department, University hospital of Setif, Algeria \\ ${ }^{2}$ Laboratory of Health and Environment, Faculty of Medicine, UFAS, SetiflUniversity, Algeria
}

*Corresponding Author: El-Hachmi Seddik, Surgery department, University hospital of Setif, Algeria, Email: sbouharati@univ-setif.dz.

\begin{abstract}
Aim: Several factors are involved in the appearance of varicose veins. Some of these factors are known. Others are poorly understood. In recent years it is better supported, particularly by surgical procedures. In this study, we try to analyze the factors that characterize a series of 62 patients operated in our department between January 01, 2016 and September 30, 2017.

Methods: The type of intervention performed depends on several factors relating to the patients and the varicose. Age, sex, weight, hereditary factor, number of pregnancies in women, sedentary lifestyle, seat of varicose vein, anatomical class are taken care of. Given the nature of these factors, which are uncertain and imprecise, we use a fuzzy inference system in the analysis of these data.

Conclusion: The proposed system takes into consideration all these uncertainties. By acting through prevention, it limits the development of certain varicose veins and therefore be limited to the most serious surgical interventions and plan a recovery at a lower cost.
\end{abstract}

Keywords: Varicose, risk factors, surgery, fuzzy logic

\section{INTRODUCTION}

If this disease has been so far not well supported, in recent years and especially for aesthetic reasons it attracts more attention [1]. When the disease is established, treatments or at the limit the surgical procedure is necessary. But before that, we try to analyze the factors that are causing it. The causes of varicose veins are multi-factorial. Also, they are of a seemingly progressive nature. It is also difficult to predict the appearance and even the evolution of these varicose veins. Cutaneous trophic changes and ulcers are observed. Our intervention can, in principle, address this issue from the epidemiological point of view. Understanding the characteristics of these patients through surveys is essential in order to assess prevalence and risk factors [2]. Several risk factors are involved including occupations that require physical effort, age, hereditary factor as well as history of venous diseases [3]. Other studies have shown that heredity as a genetic factor in addition to environmental factors play a role in susceptibility to vascular disease. This can be explained by enzyme-related abnormalities that control the metabolism of homocysteine and may be atherosclerotic vascular disease [4]; [5]. As the factors relating to the patients and the varicose (Age, sex, weight, hereditary factor, number of pregnancies in women, sedentary lifestyle, seat of varicose vein, state) are fuzzy, we found it useful to analyze them by fuzzy logic. These factors are those related to 62 patients operated in our department between January 01, 2016 and September 30, 2017 at our surgical department at Setif University Hospital in Algeria.

Before arriving at the heavy treatments and the surgical procedure, the analysis of these data makes it possible to prevent the evolution of these varicose veins. Since these factors are considered imprecise and uncertain (other factors are totally ignored and have an impact on the process), the result obtained by fuzzy inference analysis yields the most accurate result possible.

\section{VARICOSE VEIN SURGERY}

Surgery of the primary varicose of the lower limbs especially the conservation of the great saphenous vein (GSV) is the subject of 
particular attention. The effect of longevity results in degenerative diseases such as coronary arterial atherosclerosis or extremities [6]. In this case, the desirable objective whenever possible is the conservation of the GSV.

In the case where a venous obstruction is noted, the act of ablation of the varicose vein is to be avoided. This is because these are the bypass pathways responsible for the blood circulation around this obstruction. The advice is to limit activity to reduce the risk of deep vein thrombosis (DVT). Also, it is to avoid intervening on a woman during her pregnancies. Several varicose veins of pregnancy regress after delivery [6].

\section{FACTORS}

In the etiology of varicose vein can be summarized as venous dilatation and also valvular insufficiency and are triggered by unknown factors [7];[8];[9]. Among the most common factors are Age, sex, weight, hereditary factor, number of pregnancies in women, sedentary lifestyle.

According to Javien [10], women are much more affected by varicose veins than men. But this does not make sex a determining factor in the appearance of varicose veins. Other factors such as chronic venous insufficiency, age and genetic factors are for many. The study of the effect of the sex factor on the varicose can be looked for on the side of the hormones. Estradiol with a high level may be associated with clinical signs in women. The relationship between steroid hormones and varicose in humans is not accurate [11]. However, testosterone and estradiol levels in the veins of the legs compared with the cubital veins remain considerable even after treatment of saphenous veins at reflux in men. This may explain the relationship between hormones and varicose veins in the legs and arms of men [12]. Constipation may also play a role in conjunction

\begin{tabular}{|c|c|c|c|c|c|}
\hline \multirow[t]{2}{*}{ Gender } & Female & $50 \%$ & \multirow{4}{*}{$\begin{array}{l}\text { Number of } \\
\text { pregnancies }\end{array}$} & $N>5$ & $28.6 \%$ \\
\hline & Male & $50 \%$ & & $3<N<5$ & $35.7 \%$ \\
\hline \multirow{3}{*}{$\begin{array}{l}\text { Age } \\
\text { (years) }\end{array}$} & $A<20$ & $1.61 \%$ & & $N<3$ & $21.4 \%$ \\
\hline & & $46.8 \%$ & & 0 & $14.3 \%$ \\
\hline & $40<A<60$ & $38.7 \%$ & \multirow[t]{5}{*}{ Inactivity } & Forced labor & $30.4 \%$ \\
\hline \multirow{4}{*}{$\begin{array}{l}\text { Obesity } \\
\text { (BMI) }\end{array}$} & $B M I>35$ & $10.8 \%$ & & Extended standing & $43.5 \%$ \\
\hline & $30<B M I<35$ & $21.6 \%$ & & Rested profession & $21.4 \%$ \\
\hline & $25<B M I<30$ & $54.1 \%$ & & Inactivity & $8.7 \%$ \\
\hline & $20<B M I<25$ & $13.5 \%$ & & Housewife & $64.3 \%$ \\
\hline \multirow[t]{3}{*}{ Heredity } & Yes & $29.7 \%$ & \multirow{3}{*}{$\begin{array}{l}\text { Anatomical } \\
\text { class }\end{array}$} & Deep vein system & 0 \\
\hline & No & $10.8 \%$ & & Superficial vein system & $90.3 \%$ \\
\hline & Undetermined & $59.5 \%$ & & Perforating vein & $61.2 \%$ \\
\hline State & Symptomatic & $70.2 \%$ & Type of & Stripping 52 & $83.8 \%$ \\
\hline
\end{tabular}

with other factors cited in recent epidemiological studies. If obesity is often related to varicose veins it may be because of the lifestyle factor. In general, men's activity is often associated with physical activity, unlike women [13]; [14].

\section{MATERIALS AND MeTHOdS}

Sixty-two patients were operated on our service and included in this study. Questionnaires established by our service include the necessary information relating to these patients. The data collected are: age, gender, obesity, heredity with a particular focus on varicose veins, number of pregnancies in women and lifestyle. Other factors related to varicose veins, such as location, anatomical class and type of intervention performed. Confirmation of primary varicose veins was obtained by diagnosis in clinical and duplex examination. We retained the exclusion of deep vein thrombosis and probable recent infection. Patient details are summarized on Table 1.

What we see from these values is that they are characterized by uncertainty and imprecision. It is difficult to tell the difference between different age groups, for example, within a year. The age group below 19-year-old is characterized by its low rate, while the age group between 20 and 40 is distinguished by its high percentage. Really, there is not a significant difference between a 19 -year-old and a 21-year-old in terms of varicose veins, while each belongs to a different slice. The same reasoning can apply to other factors. Are we really making a difference between BMI of 29 or 31 if we set slices to 30 ? It is also very difficult also to quantify the sedentary lifestyle. For this, we have found it useful to analyze these factors by fuzzy reasoning. Fuzzy logic adapts perfectly to this type of data and supports these uncertainties. 


\begin{tabular}{|l|l|l|l|l|l|}
\hline & Complication & $21.6 \%$ & intervention & Crossectomy alone & $6.4 \%$ \\
\cline { 2 - 5 } & Asymptomatic & $2.7 \%$ & $\begin{array}{l}\text { Ligation of the perforator and } \\
\text { crossectomy }\end{array}$ & $9.6 \%$ \\
\hline
\end{tabular}

\section{FUZZY MODELING}

Les techniques de l'intelligence artificielle tendent à imiter le raisonnement humain. C'est le principe même de la modélisation intelligente [15] ; [16] ; [17]. Dans ce sens, logique floue a l'avantage de résoudre les phénomènes non linéaires. Son application dans le domaine

médical s'est diversifiée ces dernières années [18].

\subsection{Diagram of Designed Fuzzy System}

A system is built with six input variables (Gender, Age, Obesity, Heredity, Number of pregnancies and lifestyle) and two outputs (seat of varicose vein and state) Figure1.

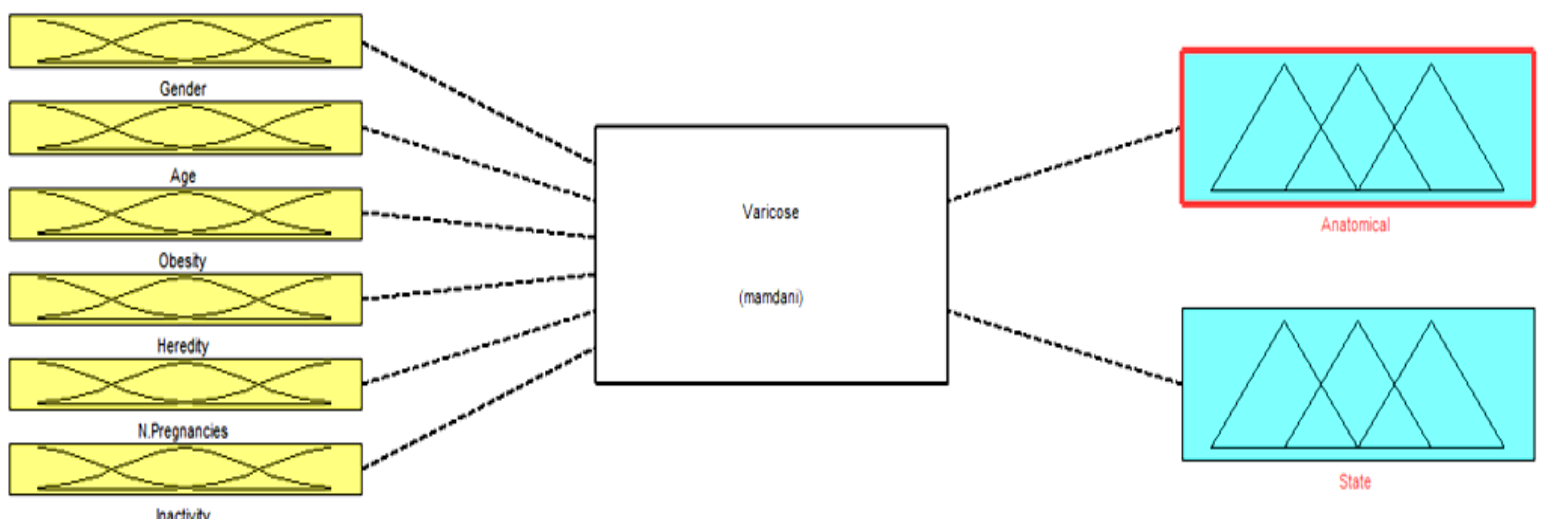

Figure1. Structure of designed fuzzy system

\subsection{Fuzzy Fication of Registered Input and Output Data}

Each input or output variable is fuzzyfied. This is to go from the numerical value to the linguistic value.

\section{Input Data}

- The variable "Age" expressed in percentage term must be fuzzyfied into linguistic term. For this, three triangular membership functions are created. Fuzzy intervals between two neighboring functions allow the uncertainties associated with this representation to be taken care of.

The functions represent: young (0-30 years); Adult (20-50 years); Old (40 years and over)

- The variable "Gender" expressed in numeric term is not fuzzyfied. We assign a value (1) to the male sex and the value (2) to the female sex.

- The variable "Obesity" where the BMI expressed in numeric term must be fuzzyfied. The functions represent BMI: Normal (20-28); Over weight (25-33); Obese (30-36); Very obese (34 and over).

- The variable "Heredity" expressed in numeric term must be fuzzyfied. We assign a value (0-2) for Yes, the value (1-3) for
Undetermined and the value Over (2) for No.

- The variable "Number of pregnancies" where the values are expressed in numeric term must be fuzzyfied to linguistic terms. The functions represents: Low $(<3)$; Average (2-5); Big (>4).

- The variable "Inactivity" expressed in numeric term must be fuzzyfied. The functions represent inactivity: Inactivity $(0-$ $2)$; Rested profession (1-3); Forced labor (24); Extended standing (3-5); Housewife (4$6)$.

\section{Output Data}

- The variable "State of varicose" expressed in numeric term must be fuzzyfied into linguistic term. For this, three triangular membership functions are created. Fuzzy intervals between two neighboring functions allow the uncertainties associated with this representation to be taken care of. We assign a value (0-2) to the Asymptomatic, (1-3) to the Complication and (2-4) to Symptomatic.

- The variable "Anatomical class" expressed in numeric term must be fuzzyfied. The functions represent anatomical: Superficial vein system (0-2); Deep vein system (1-3); Perforating vein (2-4). 


\subsection{Fuzzy Rules Database}

In general, the expression of a rule is of the form (IF ... THEN)

IF (Antecedents)...THAN (Consequence).

By referring to registered values, we assign the set of rules in this form.

Example:

IF the "Age" is young AND the "Gender" is female AND the "Obesity" is overweight AND the "Heredity" is No and "Number of pregnancies" is Low AND "Anatomical class"

\author{
[System] \\ Name $={ }^{\prime}$ Varicose ${ }^{\prime}$ \\ Type $=$ 'mamdani' \\ Version $=2.0$ \\ NumInputs $=6$ \\ NumOutputs $=2$ \\ NumRules $=87$ \\ AndMethod=' $\mathrm{min}^{\prime}$ \\ OrMethod=' $\max ^{\prime}$ \\ ImpMethod=' $\mathrm{min}^{\prime}$ \\ AggMethod=' max' $^{\prime}$ \\ DefuzzMethod='centroid' \\ [Input1] \\ Name $=$ 'Gender' \\ Range $=\left[\begin{array}{ll}0 & 3\end{array}\right]$ \\ NumMFs $=2$

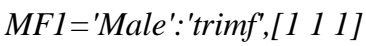 \\ MF2='Female': 'trimf', [ll 2 2 2 $]$ \\ [Input2] \\ Name $=$ 'Age' \\ Range $=\left[\begin{array}{ll}0 & 100\end{array}\right]$ \\ NumMFs $=3$ \\ MF1='Young':'trimf', [0 15 30] \\ MF2='Adult':'trimf', [20 35 50] \\ MF3='Old': 'trimf', [40 50 100] \\ [Input3] \\ Name $=$ 'Obesity' \\ Range $=[2040]$ \\ NumMFs $=4$ \\ MFI = 'Normal':'trimf',[20 2428 ] \\ MF2='Over.Weight':'trimf', [25 29 33] \\ MF3='Obese':'trimf', [30 33 36] \\ MF4='Very.Obese':'trimf', [34 36 40] \\ [Input4] \\ Name $=$ 'Heredity'
}

is Superficial vein system, THEN the "seat of varicose" is the right AND "Anatomical class" is Superficial vein system. The rule base must contain all possible combinations.

\subsection{Inference Module}

Once the database is established, it must contain all the recorded possibilities of the actual cases. This database is used to match the inputs and outputs. The elaborate system makes it possible to have an intelligent tool for predicting the localization of varicose veins and the anatomical class.

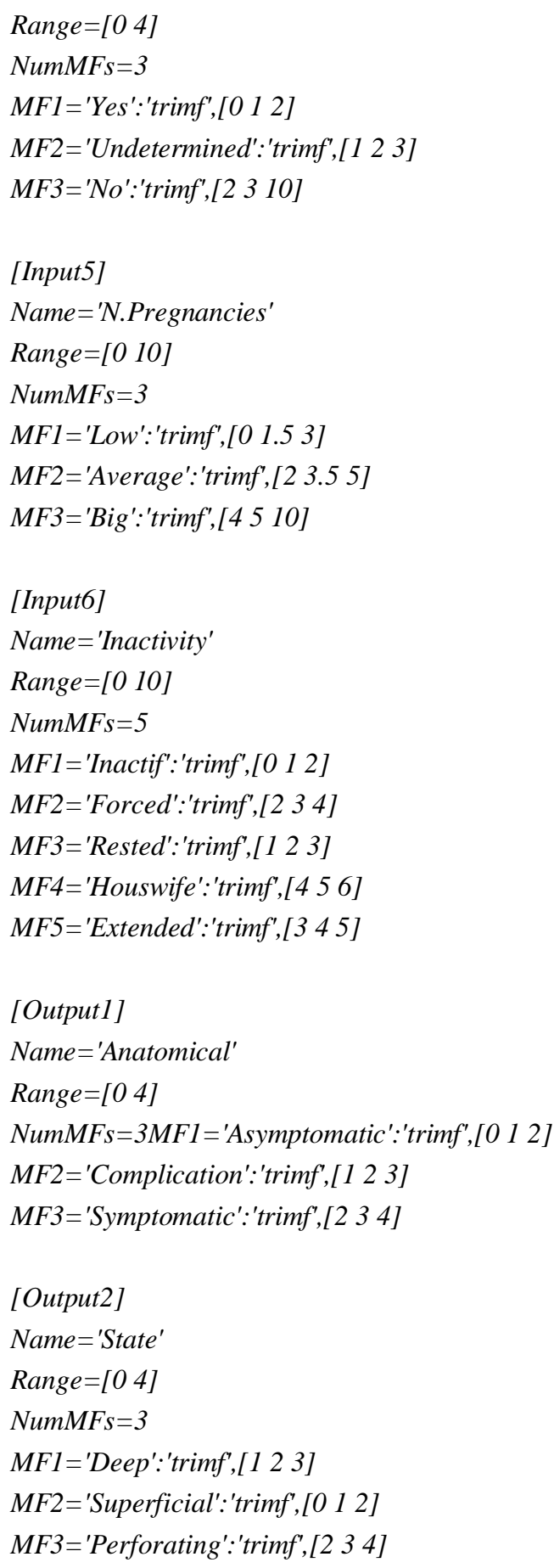




\section{RESULT AND DISCUSSION}

The established program allows introducing randomly values to the system input to automatically read the result at the output. Example at the figure 2. Each randomly set
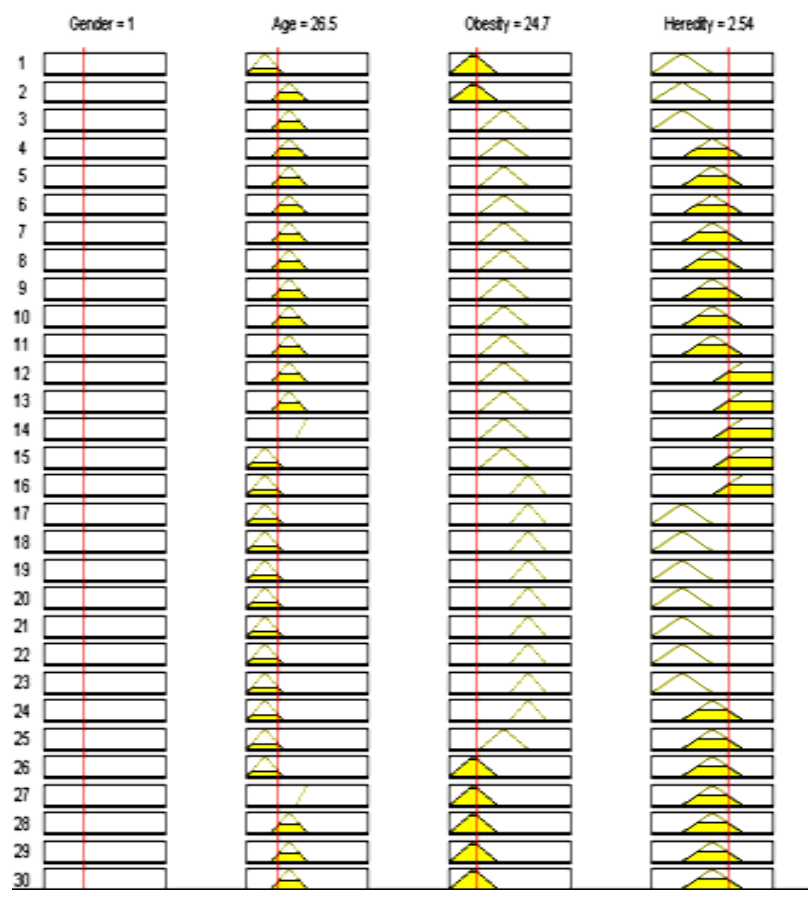

Figure2. Example application

\section{CONCLUSION}

Given the complexity of the system and the inaccuracy of the data relating to patients operated at the level of our surgery department, the proposed system makes it possible to overcome these uncertainties. Several factors can intervene in the appearance of varicose veins of the lower limbs. Some are known and cited in the literature. Others are totally unknown. Even those known, the weight of their exact influence is ignored. The same factors do not necessarily give the same effects. Anatomy and human physiology is very complex.

In the proposed study, the fundamentals of fuzzy inference make it possible to overcome these shortcomings. Each factor considered in this study is considered fuzzy variable. The registered numeric variables are fuzzyfied. By passing numeric values to linguistic variables, the system mimics human reasoning. The combination of all the possibilities in a base of the rules established from the values recorded in table 1 in linguistic term starting from the makes it possible to leave with values with the output the most optimal possible. The proposed system supports the measured factors, but it intervals fixed in the block of fuzzyfication, value refers to the pre-defined intervals previously in the fuzzyfication block. The values obtained on the outputs refer us to the fuzzyfication intervals from which we can read the anatomical class or the state of the varicose.

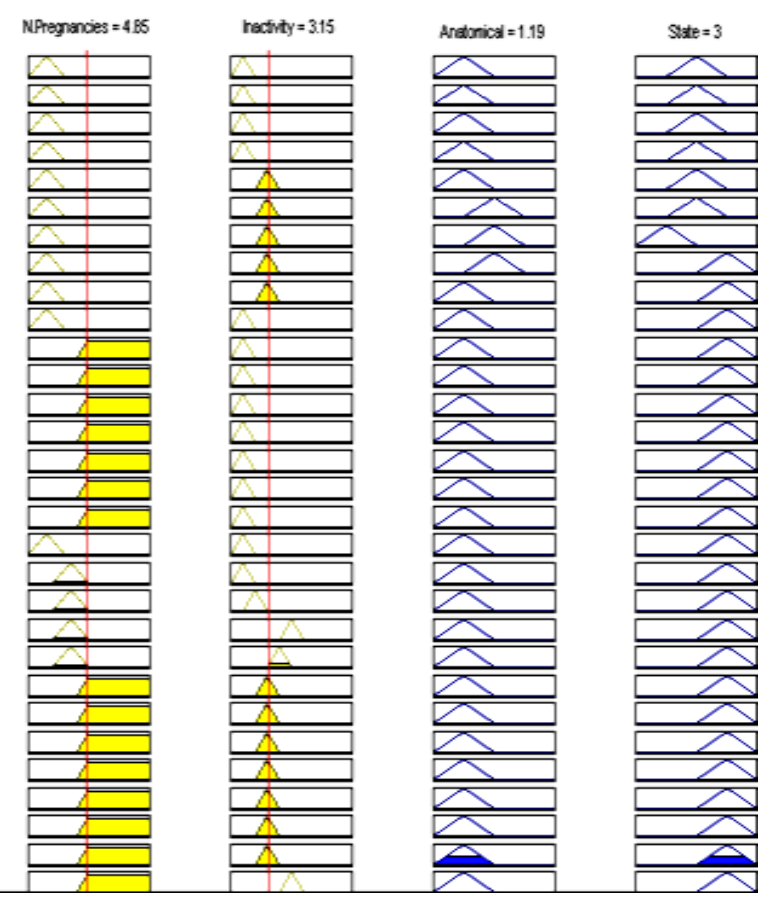

remains extensible to other factors that are not considered here and that have their effects. By randomly setting values at the input of the system, we can automatically read the results at the output. This system can be a tool for preventing and predicting varicose veins and their expected states.

\section{REFERENCES}

[1] Shankar KH. Clinical study of varicose veins of lower limbs. Int Surg J. 2017 Feb; 4(2):633636.

[2] Carpentier PH, Maricq HR, Biro C, PoncotMakinen CO, Franco A. Prevalence, risk factors and clinical patterns of chronic venous disorders of the lower limbs. A populationbased study in France. J Vasc Surg 2004; 40:650e9.

[3] Mohd S., Bhavanishankar TP. Study of risk factors and clinical assessment of lower limb varicose vein in a tertiary care hospital. International Surgery Journal Shafiuddin M et al. Int Surg J. 2017 Aug;4(8):2480-2483

[4] Nazmiye, Tülin UK, Turgay F, and Hasan FK. Potential Risk Factors for Varicose Veins with Superficial Venous Reflux. Int J Vasc Med. 2014; 2014: 531689.

[5] Kim OJ, Hong SP, Ahn JY, et al. Influence of combined methionine synthase (MTR 2756A > 
G) and methylenetetrahydrofolate reductase (MTHFR 677C > T) polymorphisms to plasma homocysteine levels in Korean patients with ischemic stroke. Yonsei Medical Journal. 2007; 48(2):201-209.

[6] Hamilton AR, Mariângela G, Winston BY. Varicose vein surgery in lower limbs with preservation of the great saphenous vein $\mathrm{J}$. vasc. bras. 2009; vol.8 no.2 Porto Alegre.

[7] Meghdadi S, Rodrigues M, Oguogho A, Santler R, Sinzinger H. 8-Epi-PGF2 $\alpha$ and 6-oxoPGF1 $\alpha$ in human (varicose) veins: influence of age, sex, and risk factors. Angiology. 2003; 54(3):317-324

[8] Rizzi A, Quaglio D, Vasquez G, et al. Effects of vasoactive agents in healthy and diseased human saphenous veins. Journal of Vascular Surgery. 1998; 28(5):855-861.

[9] Glowinski J, Glowinski S. Generation of reactive oxygen metabolites by the varicose vein wall. European Journal of Vascular and Endovascular Surgery. 2002; 23(6):550555. [PubMed]

[10] Yao JS. Venous disorders-reflections of the past three decades. Journal of Vascular Surgery. 1997; 26:727-735.

[11] Zöller B, Ji J, Sundquist J, Sundquist K. Family history and risk of hospital treatment for varicose veins in Sweden. British Journal of Surgery. 2012; 99(7):948-953.

[12] Kendler M, Makrantonaki E, Tzellos $\mathrm{T}$, Kratzsch J, Anderegg U, Wetzig T,
Zouboulis C, Simon JC Elevated sex steroid hormones in great saphenous veins in men. $\mathrm{J}$ Vasc Surg 2010, 51(3):639-646.

[13] Kendler M, Kratzsch J, Wetzig T, Simon JC. Sex steroid hormones are not altered in great saphenous veins after varicose vein treatment in male patients. The Journal of Venous Disease. 2014; Volume: 29 issue: 5, page(s): 310-317.

[14] Awien A. The influence of environmental factors in chronic insufficiency venous. Angiology. 2003;54(1):S19-S31. [PubMed]

[15] Beebe-Dimmer JL, Pfeifer JR, Engle JS, Schottenfeld D. The epidemiology of chronic venous insufficiency and varicose veins. Annals of Epidemiology. 2005;15(3):175-184.

[16] Dumitrache I., "ngineriaReglarii Automate (Automatic Control Engineering), Politehnica Press, 2005

[17] Dumitrache I., Constantin N., Dragoicea M., Reteleneurale (Neural networks), Matrix Press, 1999

[18] Dumitrache I., Buiu C. Algoritmi genetici. Principii fundamental esiaplicatii in automatic (Genetic algorithms. Fundamental principles and applications in automatics), Mediamira Press, 2000

[19] Bouaoud S., Bouharati K., Kara L., Boukhaouba H., Bouharati S., Mahnane A., Hamdi-Cherif M. Tobacco as a risk factor of larynx cancer: Artificial neural network modeling. Averroes European Medical Journal. 2017. Volume 3. Number 2.

Citation: El-Hachmi Seddik, Khenchouche Abelhalim, Bahar Abdelaziz. Intelligent Analysis of Some Factors Characterizing Patients Operated For Varicose Veins at Setif University Hospital -Algeria. ARC Journal of Cardiology. 2017; 3(2) 21-26. doi: dx.doi.org/11.20431/2455-5991.0302004.

Copyright: (C) 2017 Authors. This is an open-access article distributed under the terms of the Creative Commons Attribution License, which permits unrestricted use, distribution, and reproduction in any medium, provided the original author and source are credited. 